\title{
Characterization and analysis of naturally fractured gas reservoirs based on stimulated reservoir volume and petro-physical parameters
}

\author{
Ali Al-Rubaye ${ }^{1}\left[\right.$ [ $\cdot$ Ahmed Al-Yaseri ${ }^{2} \cdot$ Muhammad Ali $^{3} \cdot$ Hisham Ben Mahmud $^{4}$
}

Received: 25 October 2020 / Accepted: 29 December 2020 / Published online: 7 January 2021

(c) The Author(s) 2021

\begin{abstract}
Fracture is one of the most important geological phenomena that affect the production of hydrocarbon compounds in broken carbonate reservoirs. However, fracture controlling factors must be combined with well data to achieve accurate fracture modeling. Therefore, structural data, drilling data, well flow diagrams, cores data, wells production data, and dynamic reservoir data have been considered here. Finally, by combining the above-mentioned information and through statistical and mathematical methods, the mechanism of fracture creation, general trends, and dominant fracture patterns are determined. These patterns are directly related to the tectonic regime and the stresses governing the region. For the first time, in this paper, we divided Zubair carbonate gas reservoir into 10 zones based on porosity and water saturation, and shale volume variation. We conclude that just four-zone of these are economic producible. Besides, the dominant lithology of this formation is more than limestone and a small number of thin shale layers. We defined types of cross-sectional petro-physical graphs and confirmed them by the geological graphic diagram prepared at the head.
\end{abstract}

Keywords Naturally fractured reservoirs · Petro-physical parameters · Fracture characterization · Well log interpretation · Formation micro-imager (FMI) $\cdot$ Image logging $\cdot$ Borehole images

\section{Introduction}

Investigation of natural fractures in gas reservoirs is an important factor in controlling flow at the stages of production and development of the field (Luffel et al. 1993); fractures also have an important influence on the porosity and permeability of the rock and facilitate the movement of fluids. The presence of fractures, even small fractures, has a significant effect on permeability (Sakhaee-Pour and Bryant 2012). Awareness and understanding of the patterns and how they are distributed in each field allows for the correct design, drilling locations of wells to increase production

Ali Al-Rubaye

ali.rubaie38@gmail.com

1 Gudea Geoscience Group, Thi Qar, Iraq

2 School of Engineering, Edith Cowan University, Joondalup, WA 6027, Australia

3 Western Australia School of Mines, Minerals, Energy and Chemical Engineering, Curtin University, 26 Dick Perry Avenue, Kensington, WA 6151, Australia

4 Department of Petroleum Engineering, Curtin University, Miri, Sarawak, Malaysia and maximum efficiency of the reservoir, and reduce costs (Ben et al. 2012). In the study of fractures of hydrocarbon reservoirs, in general, various data such as construction data (underlying and submerged surfaces), drilling data, well flow diagrams, core data, wells production data, and dynamic reservoir data are used.

Fractures in the gas fields of the Arabian Basin have a major role in the migration and production of hydrocarbon reservoirs (Al-Rubaie and Ben Mahmud 2020); especially the Zubair Formation and the carbonate reservoirs of Iraq which have a worldwide reputation in this regard.

These fractures are mainly of structural origin and during the compressive phases associated with the Alpine climatic conditions, along with the horizontal movement of the Arabian continental crust along the NNE trend, shell shortening and folding of the sediments of this basin have been created. The presence of fractures or even small fractures, has a significant effect on permeability, also knowing, understanding patterns and fracture's distribution in each field enables the proper design of wells drilling locations to maximize production of the reservoir and reduce costs.

$\mathrm{S}$ Gas field is the largest gas field in Iraq, with an area of $21 \mathrm{~km}$ by $13 \mathrm{~km}$, located in the area of Basra plain adjacent 
to the borderline between Iran and Iraq, $30 \mathrm{~km}$ southwest of Basra city in the area of Arabian plain. In the mid-sixties, with the arrival of visual charts to the oil industry, a huge revolution was created in this area (Al-Rubaie and Ben Mahmud 2020). The graphic tool, due to the high resolution and the creation of a virtual image of the well wall, allowed the identification of small-scale phenomena. These graphs provide a virtual image of the well wall, indicating the physical properties of the well wall. Using graphic charts to reservoir geologists also allows small structures of tectonic or sedimentary scale to be identified within the well wall.

The presence of fractures in most outcrops is a very common issue, and this means that most of the oil and gas reservoirs in the world are likely to be affected by this phenomenon (Cho et al. 2013). Natural problems can cause heterogeneity or dissonance in reservoirs and affect fluids flow. Thus, in the development and management of reservoirs, a detailed description of the network reservoir fractures is very important.

Petro-physical evaluation is the science of interpreting the information from well logs to study the reservoir quality of different parts of the formation and reservoir zoning to determine the most suitable zones for optimum utilization of reservoirs and development of gas fields (Al-Rubaie and Ben Mahmud 2020). The importance of reservoir description, due to its ability to detect the basic geological and petrophysical parameters affecting fluid motion in hydrocarbon areas, is a major geological and petro-physical parameter that influences fluid motion.

According to the above, most carbonate formations have wide variations in their petro-physical properties, including in homogeneities and pore size, such as, for example, permeation estimation, among which is the determination of which in this type of tanks is very complicated and difficult to account comes (Hu et al. 2014). Typically, before geologists and reservoir engineers can design a suitable reservoir model, and they need to have a variety of processes that can be used to evaluate the properties of carbonate reservoir rocks as best they can (King 2010).

Considering the importance of recognizing the distribution and frequency of fractures and other determinants of reservoir quality, in optimum exploitation of gas reservoirs and the development of gas fields. In this study, using well $\log$ charts, in particular illustrators, to analyze fractures in $\mathrm{S}$ gas field wells have been paid. Firstly, image diagrams will be processed and corrected in wells studied in Geolog software. Then, using graphic diagrams, various types of natural and artificial structures were identified and interpreted, and their orientation would be measured.

\section{Background about naturally fracture gas reservoir}

Fractures are more characteristic of large carbonate gas fields (Wu et al. 2020) and in rocks due to small or large positive or negative changes in stress fields. In carbonate rocks, tectonic pressures, dissolution and collapse, crystallization, and so on can create fractures. Fractures can occur during sedimentation, but the effect of these fractures on the reservoir properties is negligible. Fractures are usually very small for porosity, and the maximum porosity due to fractures rarely reaches two percent of the total volume of the reservoir stone, but the effect of fractures on the permeability of the reservoir is amazing (Zhao et al. 2014).

The information and knowledge about the fracture are not only effective in investigating hydrocarbon recovery from reservoirs, but also it can be useful in plans for secondary recovery, and so on. The presence of fractures and gaps in the rate of utilization and the final withdrawal of gas reservoirs, especially in carbonate formations, plays an important role (Fig. 1).

\section{Petro-physical properties of naturally fractured gas reservoir}

Charting from wells is one of the specialty fields in oil and gas exploration and extraction, which coincided with the development of devices for graphing, interpretation, and evaluation of charts taken from wells in the oil industry, titled Engineering Petro-physics is also being developed. Petro-physics is the study of rock properties and their interaction with fluid, which can be gas, liquid hydrocarbons, or aqueous solutions, based on charts and laboratory measurements, and mathematical and physics laws.

Since petroleum tanks have to be porous and permeable, petro-physics focuses on the properties of porous and permeable rocks. By combining geological information, drilling,
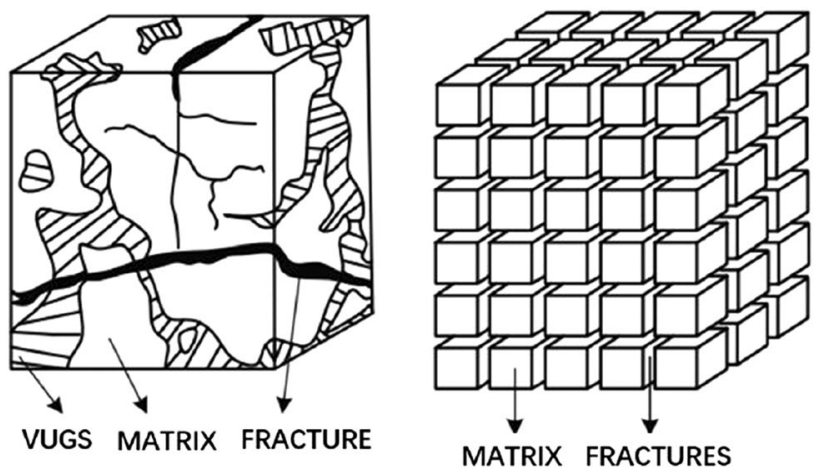

Fig. 1 The double-porosity model proposed by Warren and Root (1963) 
core, and information obtained from graphing, we try to provide a petro-physical model of the formation and fluid within it that is the best and most appropriate answer to all of this information.

\section{Petro-physical evaluation of naturally fractured gas reservoir}

Petro-physical evaluation is the science of interpreting the information obtained from well logs to study the reservoir quality in different parts of the formation and reservoir zoning to determine the most suitable zones for optimal reservoir exploitation and development of gas fields ( $\mathrm{Ge}$ and Ghassemi 2012).

The petro-physical studies aim is to investigate the quality of the reservoir in different parts of the formation, reservoir zoning to determine the most suitable zones for optimal use of the reservoir, and to develop more informed gas fields. Determining the type of lithology, total porosity, effective porosity, water saturation, and hydrocarbon saturation and calculation of shale volume are the most important parameters that should be determined in petro-physical assessment to determine the quality of the reservoir. The correct estimation of these parameters plays an effective role in reservoir modeling and the degree of success of many exploration, drilling, development, and operation of oil and gas reservoirs depends on the accuracy of these parameters. In the oil industry, reservoir parameters are determined by two common methods for evaluating well-logging data (for example, Fisher et al. 2002): 1-Direct method: The title of the kernel analysis evaluation 2-Indirect method: The use of core analysis.

Since the production of the reservoir will always be accompanied by a drop in pressure, the use of gas injection is a good way to prevent overpressure of the reservoir. We will further examine the impact of the properties on the recycling and strategy of recycling. Recognition of lithology type, calculation of shale volume (Vsh), total porosity (PHIT), effective porosity (PHIE), and water saturation (SW) are the most important parameters that are determined in petro-physical evaluation to determine the reservoir quality of formations (Mayerhofer et al. 2006). Figure 2 shows the effective parameters in petro-physical evaluation.

\section{Application of FMI visual diagram in petro-physical evaluation of reservoirs}

In the mid-1980s, Schlumberger Company produced the first electric tool called FMS (Mayerhofer et al. 2010). In 1991, the FMI instrument with a high resolution and a higher coverage than FMS was introduced (Mayerhofer et al. 2010). The FMI tool is a new generation of imaging tools that doubles the wall coverage compared to the FMS (Mayerhofer

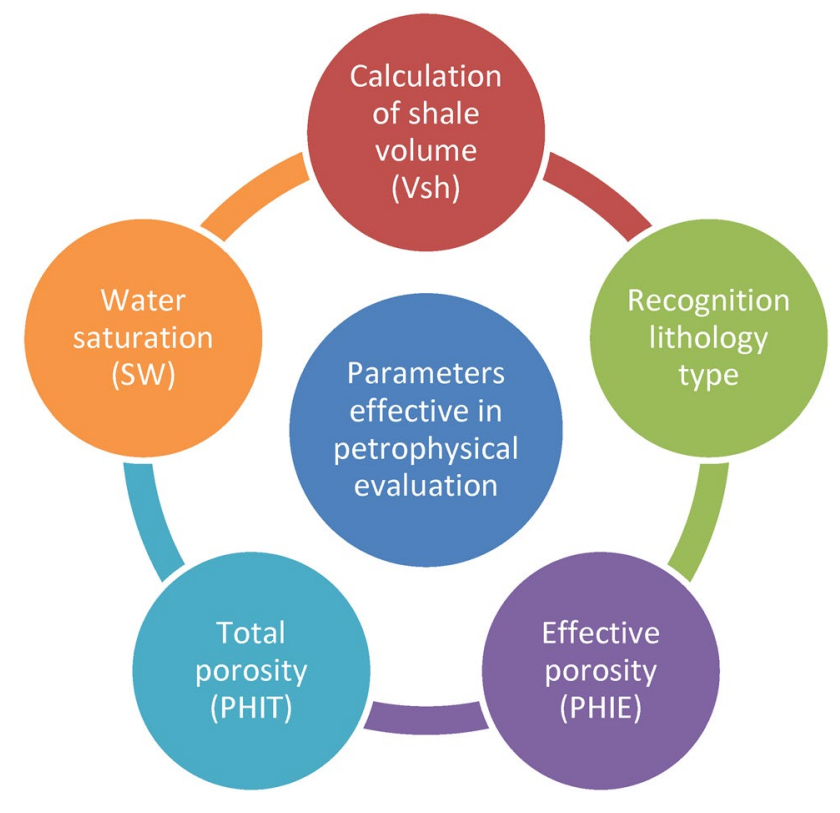

Fig. 2 Parameters effective in petro-physical evaluation

Table 1 Depth of S gas field formations

$$
\begin{aligned}
& \text { S-5 well } \\
& \text { Zubair Formation } \\
& \text { Depth (m) 2938-2928 } \\
& \text { Layers } 3
\end{aligned}
$$

et al. 2010). The FMI device has many uses in reservoir engineering and geology (Mayerhofer et al. 2010). The basis of these tools is to measure the resistance of the formations, and the result is an image interpreted for the study and analysis of various phenomena. The three most commonly used tools are visual instrument (OBMI), visual tools (FMS), and visual instrumentation (FMI).

\section{Research methodology}

In the oil industry, to study the application of fractures within the reservoirs, the use of directional cores and imaging charts is essential. Generally, these charts were used to study and measure geometric parameters of layers, faults, and fractures (stretching, slope, and direction), detection of open, semi-open, and closed fractures, diagnosis of dense and irregular sections in the reservoir, diagnosis of acetylolitis and anhydrite, determination for local stress, and so on.

Empirical and mathematical relations are used to evaluate the effective parameters on reservoir quality using graphic diagrams and petro-physical modeling and their interpretation using the software of Geolog, to determine the porosity, permeability, and type of lithology, the amount of shale, water saturation, and determination of the surface

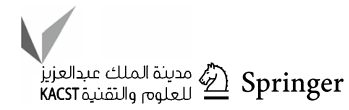


of the reservoir fluid contact with fractures paid. Empirical and mathematical relations are used to prepare the optimal model according to the type of lithology and fluids of the formation. Shale volume can be calculated from gamma spectrometer logic and existing relationships. Chalk Changes in Gamma Chart Increases in Chalk Departments and Horizons. According to carbonate lithology with a low content of shale and fluid formations, (oil and water filtration), experience shows that Archi's relationship with the Indonesia-based model has given credible results.

The results obtained from the processing and interpretation of conventional reservoir diagrams with geological data including graphic diagrams and descriptions of core samples and drill bits will be adapted. Besides, the results obtained from illustrators using Geolog software and the results obtained by processing and interpreting reservoir charts

Fig. 3 Situation of S gas field relative to neighboring fields

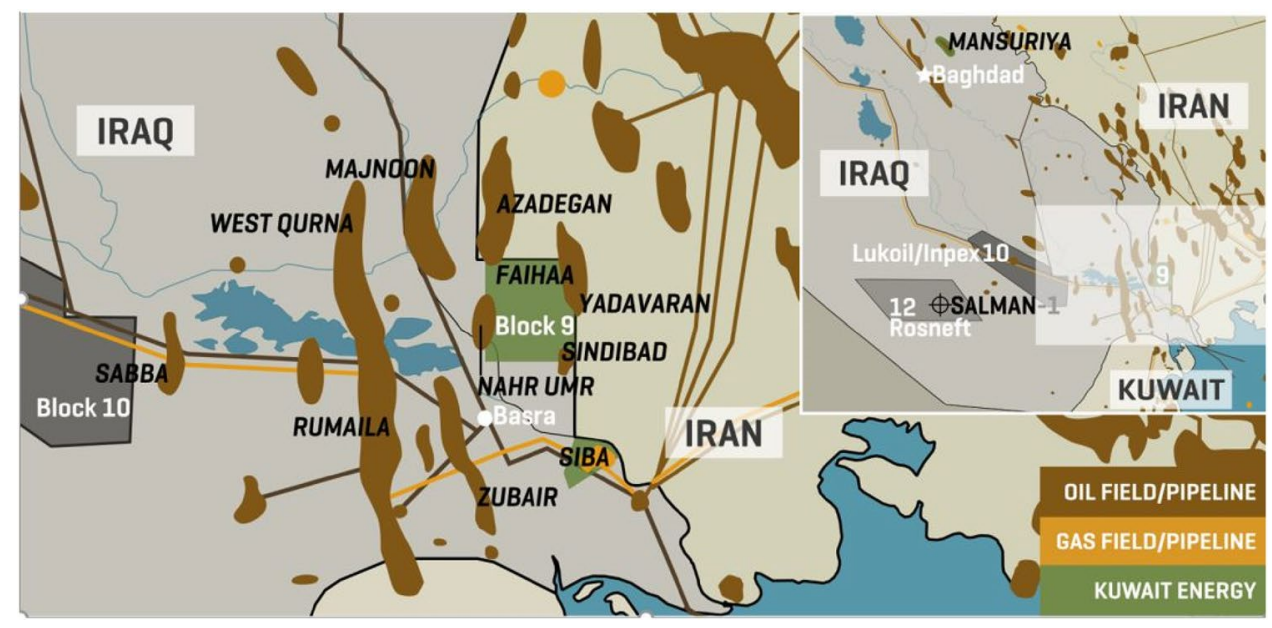

Table 2 Petro-physical properties of S gas field in northern and southern parts

\begin{tabular}{|c|c|c|c|c|c|c|c|c|c|c|c|c|}
\hline \multirow[t]{3}{*}{ Zone } & \multicolumn{12}{|l|}{ Sector } \\
\hline & \multicolumn{3}{|c|}{ Sector 1} & \multicolumn{3}{|c|}{ Sector 2} & \multicolumn{3}{|c|}{ Sector 3} & \multicolumn{3}{|c|}{ Sector 4} \\
\hline & $\mathrm{N} / \mathrm{G}$ & PORO & SWC & N/G & PORO & SWC & N/G & PORO & SWC & $\mathrm{N} / \mathrm{G}$ & PORO & SWC \\
\hline \multicolumn{13}{|c|}{ North part } \\
\hline Zone-A & 0.555 & 0.1023 & 0.242 & 0.68 & 0.1142 & 0.2637 & 0.37 & 0.1228 & 0.3002 & 0.43 & 0.1113 & 0.3421 \\
\hline Zone-B & 0.42 & 0.0835 & 0.3226 & 0.54 & 0.1066 & 0.288 & 0.19 & 0.1058 & 0.3514 & 0.22 & 0.0922 & 0.3583 \\
\hline Zone-C & 0.564 & 0.1051 & 0.2785 & 0.68 & 0.1273 & 0.2321 & 0.67 & 0.14 & 0.3257 & 0.23 & 0.1232 & 0.4309 \\
\hline Zone-D & 0.27 & 0.112324 & 0.3133 & 0.24 & 0.1194 & 0.2392 & 0.1 & 0.128 & 0.338 & 0.09 & 0.0914 & 0.3559 \\
\hline Zone-E & 0.444 & 0.1307 & 0.2819 & 0.49 & 0.1271 & 0.2336 & 0.38 & 0.1356 & 0.3223 & 0.08 & 0.1219 & 0.3708 \\
\hline Zone-F & 0.711 & 0.1175 & 0.2265 & 0.54 & 0.1132 & 0.2547 & 0.29 & 0.126 & 0.419 & 0.06 & 0.0883 & 0.3915 \\
\hline Zone-G & 0.38 & 0.144 & 0.23 & 0.55 & 0.1197 & 0.2647 & 0.23 & 0.163 & 0.423 & - & - & - \\
\hline Zone-H & 0.03 & 0.073 & 0.32 & 0.13 & 0.119 & 0.3 & - & - & - & - & - & - \\
\hline Sector & 0.475 & 0.113 & 0.262 & 0.435 & 0.118 & 0.255 & 0.384 & 0.133 & 0.347 & 0.351 & 0.108 & 0.371 \\
\hline \multicolumn{13}{|c|}{ Southern part } \\
\hline Zone-A & 0.83 & 0.145 & 0.1249 & 0.76 & 0.1226 & 0.1709 & 0.78 & 0.1282 & 0.1819 & 0.66 & 0.1375 & 0.2791 \\
\hline Zone-B & 0.61 & 0.1014 & 0.2333 & 0.7 & 0.111 & 0.1662 & 0.65 & 0.1266 & 0.2204 & 0.4 & 0.1215 & 0.3327 \\
\hline Zone-C & 0.91 & 0.1416 & 0.1162 & 0.88 & 0.1262 & 0.1553 & 0.89 & 0.1657 & 0.1623 & 0.7 & 0.1468 & 0.3035 \\
\hline Zone-D & 0.56 & 0.094 & 0.2887 & 0.53 & 0.1087 & 0.2234 & 0.7 & 0.1332 & 0.2246 & 0.76 & 0.1161 & 0.3276 \\
\hline Zone-E & 0.65 & 0.1322 & 0.23 & 0.81 & 0.1122 & 0.2041 & 0.79 & 0.1292 & 0.2116 & 0.57 & 0.1386 & 0.2848 \\
\hline Zone-F & 0.67 & 0.1265 & 0.2086 & 0.74 & 0.1117 & 0.2061 & 0.54 & 0.1357 & 0.2529 & 0.37 & 0.091 & 0.331 \\
\hline Zone-G & 0.61 & 0.1434 & 0.2597 & 0.71 & 0.1199 & 0.2868 & 0.45 & 0.1488 & 0.3421 & 0.27 & 0.191 & 0.236 \\
\hline Zone-H & - & - & - & 0.08 & 0.0654 & 0.376 & - & - & - & - & - & - \\
\hline Sector & 0.507 & 0.128 & 0.193 & 0.564 & 0.116 & 0.200 & 0.510 & 0.139 & 0.217 & 0.427 & 0.126 & 0.302 \\
\hline
\end{tabular}


adapted to petro-physical charts will be used for evaluation and validation in the $\mathrm{S}$ gas field.

\section{Field of study (S gas field)}

The $\mathrm{S}$ gas field is the largest in the south of Iraq. Its discovery dates back to 1968 , and in the region of $13-21 \mathrm{~km}$, the Basra plain is located adjacent to the borderline of Iran and Iraq, located $30 \mathrm{~km}$ southwest of Basra city.

This field has four production formations A, B, E, and D. The amount of gas reserves in the field is about $1.1 \mathrm{tcf}$ gas, which is expected to occur in case of implementation of extraction programs and full hydraulic fracturing. The development plan of the field was approved in 2010, the purpose of this project was to develop the southern part of the $S$ gas field in two phases. The capacity of the field was estimated at $1.1 \mathrm{tcf}$ gas. S gas field is controlled by the Ministry of Oil Baghdad, whose development activities are carried out by Kuwait Energy.

The field has various gas reservoirs. In addition to the reservoirs that produce gas from the, A, B and D, E formations also have gas in this field, but so far there have not been any complete experiments to prove the economics of gas production. (Although the new information we obtained from this field shows that there is also extractable gas in some of these clusters) (Fig. 3).

\section{Wells studied}

The study is based on the S-5 well of S gas field (Zubair Formation). The specifications of these wells are given in Table 1. Petro-physical properties are presented in Table 2.

\section{Software used (Geolog software)}

Geolog software is designed for professional use in the field of hydrocarbon reserves exploration and extraction. This application is an advanced tool for geophysical and petro-physical assessments and is used in the charts of wells. Geolog software is also the best geological analysis tool that can manage and integrate data well.

Moreover, the main ability and application of this software are in understanding the geological and petro-physical properties of a specific formation. Various sections of the software provide the possibility of achieving very accurate results for petroleum geologists and petro-physicists. To carry out all petro-physical interpretations, Geolog allows
Fig. 4 Construction form and position of wellheads in S field
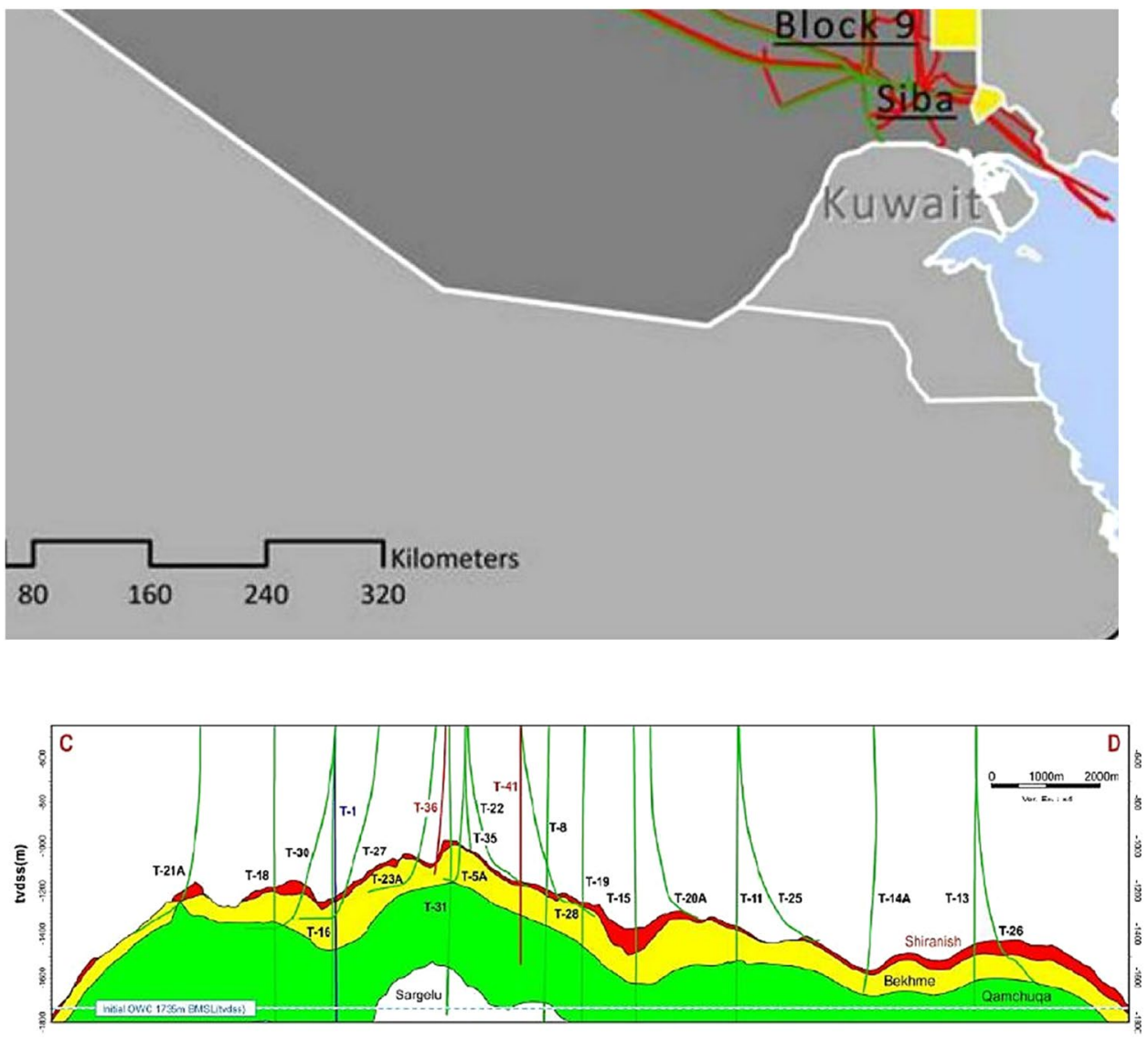
the use of both major methods of petro-physical analysis, a definite and probable method.

\section{Results}

The shape of the S gas field was similar to an asymmetrical elliptic with the north-south trend, with the slope of the layers in the south of the anticline less than the northern part, but the slope in the eastern and western parts of the anticline seems to be the same. The anticline is relatively narrow in the north and wider in the south. The $\mathrm{S}$ anticline has three boundaries that depend on the $\mathrm{A}, \mathrm{B}$, and $\mathrm{D}, \mathrm{C}$ horizons, respectively (Fig. 4).

Based on the seismic sections, the loose buildings in these horizons lack structural constructions and consist of two northern and southern hills that are larger than the southern hills. There is a sudden change along the axis of the building from north to south, which may be the location of these trend changes consistent with linear structural phenomena such as faults. The flight faults are seen in the anticline core.

These faults are seen in the Jurassic and older horizons. In higher horizons, the effects of these faults are not observed. The existence of irrelevant horizons, such as Gutennia, reduces the displacement of these faults in higher horizons. These faults are probably related to pseudo-faults or their branches and indicate their role in the formation of Zubair's building (Al-Rubaie and Ben Mahmud 2020). The Zubair building is formed by the re-activation and uplifting of the Arabian normal faults along the Arabian ancient lagoons.
Fig. 5 Simplified stratigraphy of the region that has large lithologic sequences and major tectonic events in Zubair and Basra plains

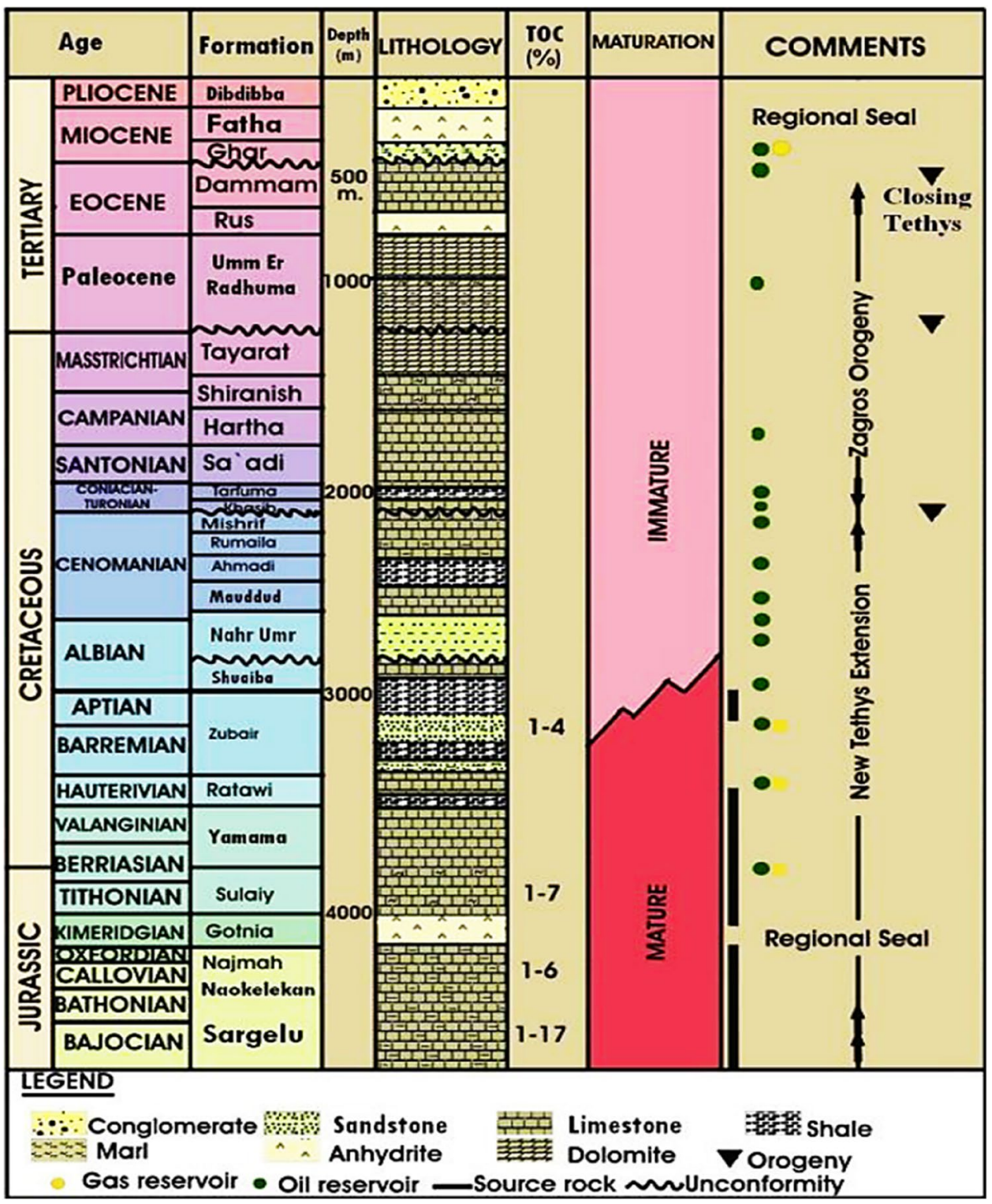


Fig. 6 Building slope display

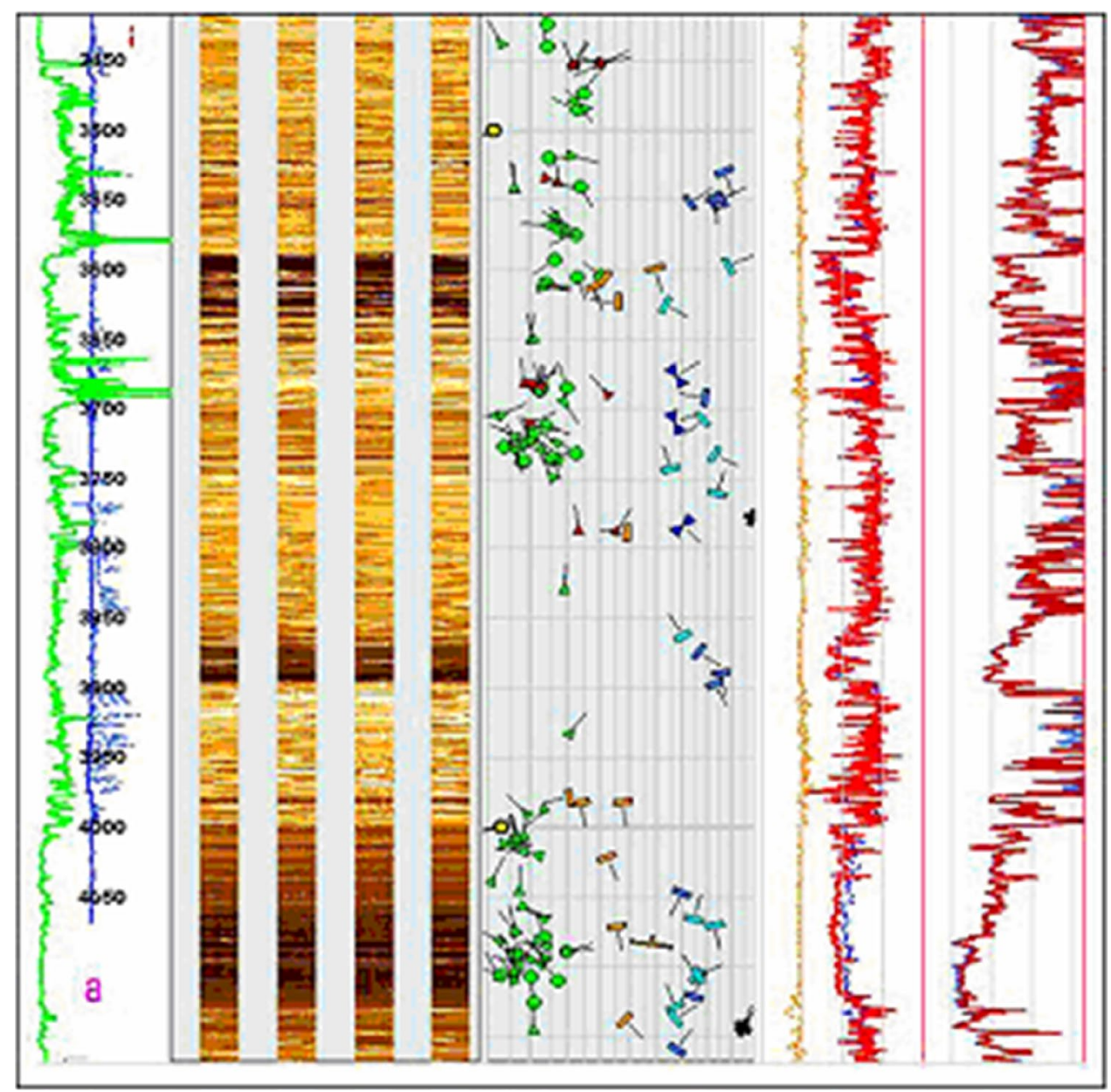

\section{Zubair formation in S field}

This formation in all wells has gas and only in well No. 7 watershed. Zubair Formation in other fields located in Basra plain also has good reservoir facies. Figure 5 shows a simplified stratigraphy of the region showing large lithologic sequences and major tectonic events in Zubair and Basra plain desertification.

\section{Fracture evaluation}

Fracture evaluation can be divided into direct and indirect methods. In the direct method, core information and graphic graphs are used. The most realistic information on the fracture of the reservoir and the data obtained from the core can be obtained by direct observation of core samples. The shape diagram is a virtual shape of the well wall, which is based on the physical properties of the formation, such as electrical resistance and acoustic distortion (Mayerhofer et al. 2010).

To evaluate fractures, firstly, the fractures were interpreted from well-shaped diagrams of the South S gas field.
Drilling in this well was carried out vertically with a deviation of $3^{\circ}$ and graphing in a well with a diameter of $154 / 6$ inches. The shape diagram of the microstructure tool was performed at depth distances of 3417 to $4167 \mathrm{~m}$ in the Sulaiy Formation. Based on the interpretation of these graphs, the mean structural slope for the Zubair Formation is $7^{\circ}$ west and $30^{\circ}$ north (N30W) (Fig. 6).

Based on the 32 fractures taken from the microstructure form graph images, there were 3 types of fractures in the Zubair Formation in this well. Three cavity fractures with $57^{\circ}$ east along east, 15 possible open fractures with slope of $57^{\circ}$ to $77^{\circ}$ and $2^{\circ}$ west of 25 southeast-(S25W) 25 north and east 75 (N25E) northwest 75 (N75E) north (N75W), 14 closed fractures with a slope of $52^{\circ}$ to $80^{\circ}$, and three parallel with the coordinates of West 75 Northeast 75 (N75W) South and East 25 (S75E) Southwest 25-(S25E) North and West 60 (N25W) South East (S60W) and 60 North (N60E) (Fig. 7).

The presence of fractures due to horizontal stresses due to damages of the well wall represents the lowest horizontal stress $(\delta 1)$ and in the direction of NNE-SSW, the depth of $4147 \mathrm{~m}$ is shown in Fig. 8. 


\section{Dip Azimuth Rosette}
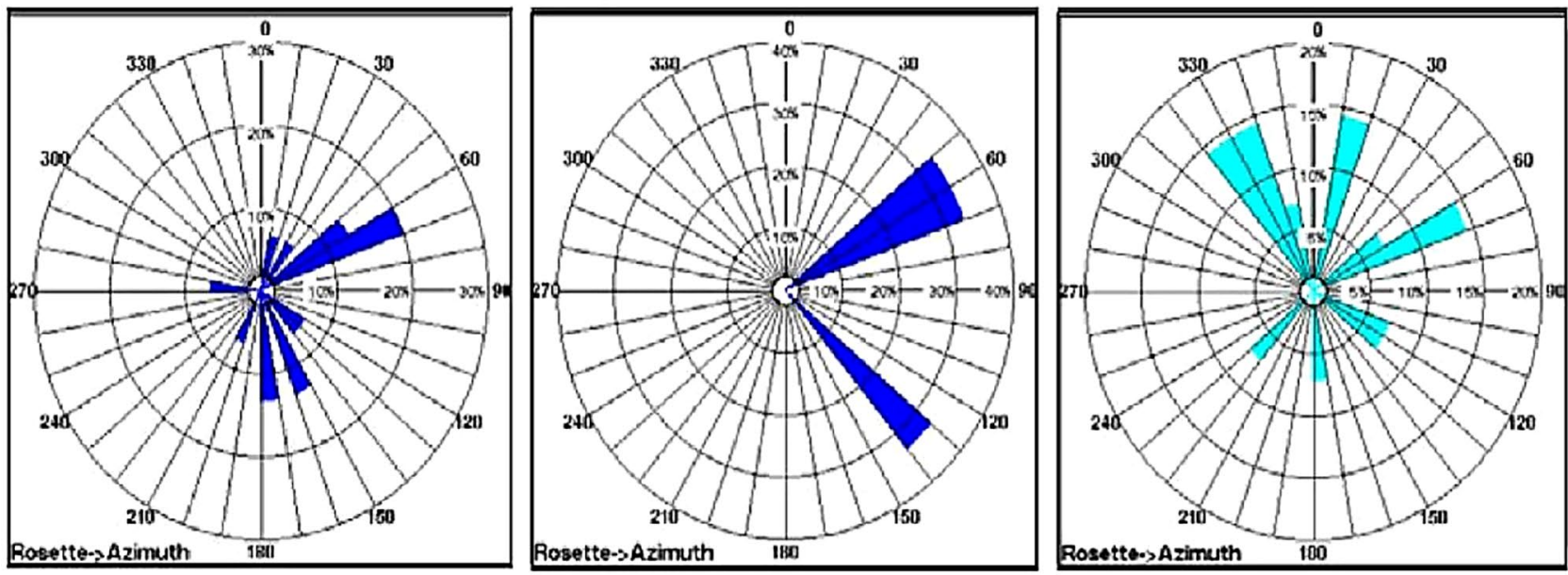

\section{Strike Azimuth Rosette}
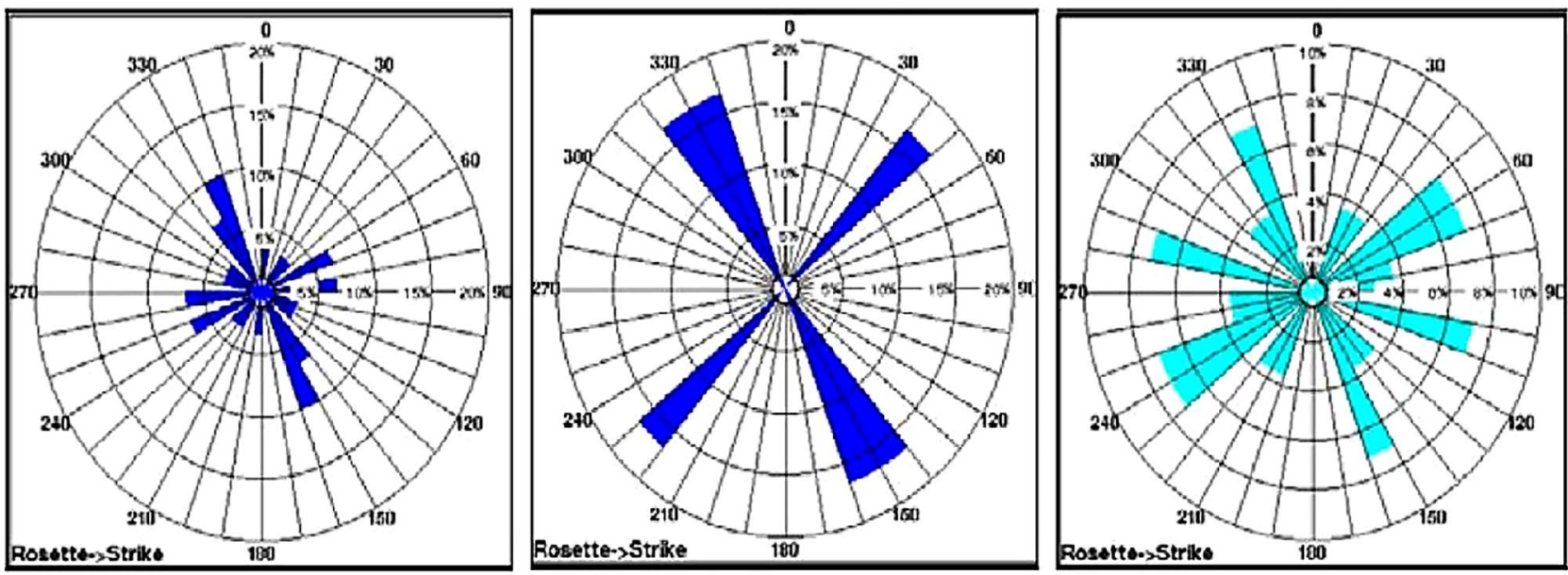

Dip Inclination Histogram
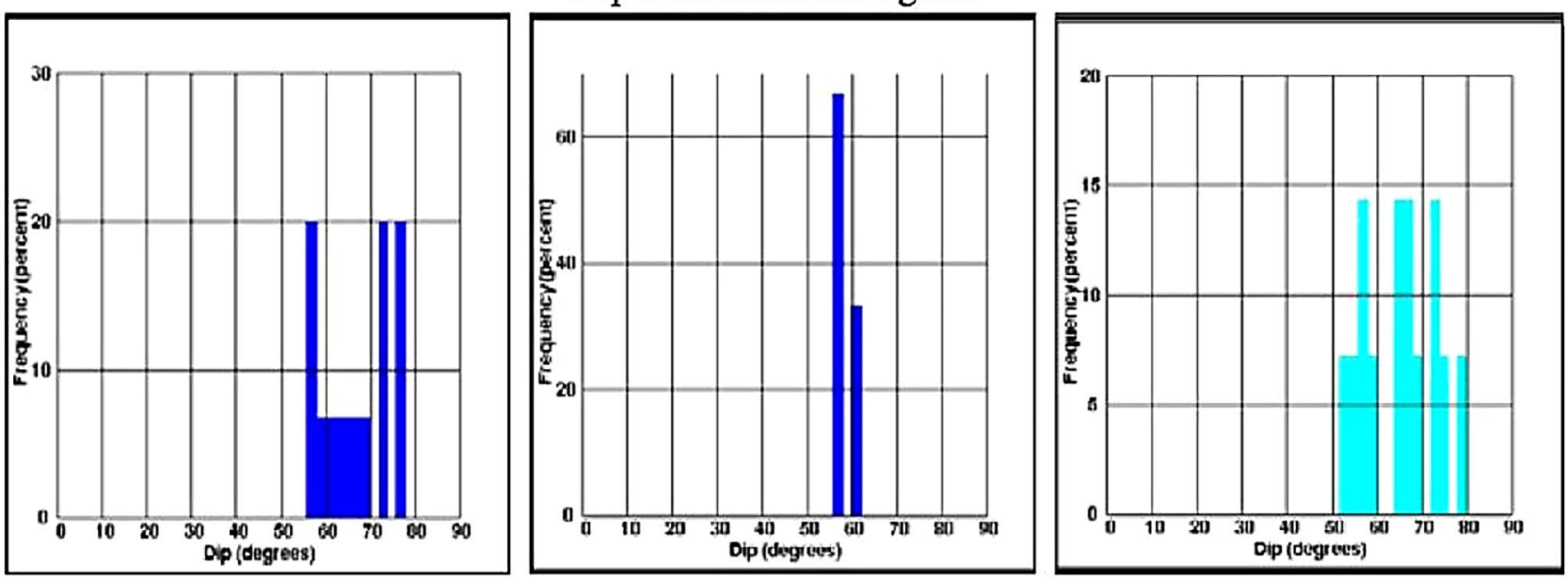

Fig. 7 The slope and directional striated data, respectively, in closed fractures, cavities, and open probable types of diagonal fracture

Accordingly, for the maximum horizontal stresses of NNE-SSW, which corresponds to the general trend of tensions on the Arabian Basin (Fig. 9).
Correlation between fracture and corneal fractures can be used with more confidence in the results of microstructure shaper diagrams in creating reservoir models. 
Fig. 8 Fractures from damages to the well wall

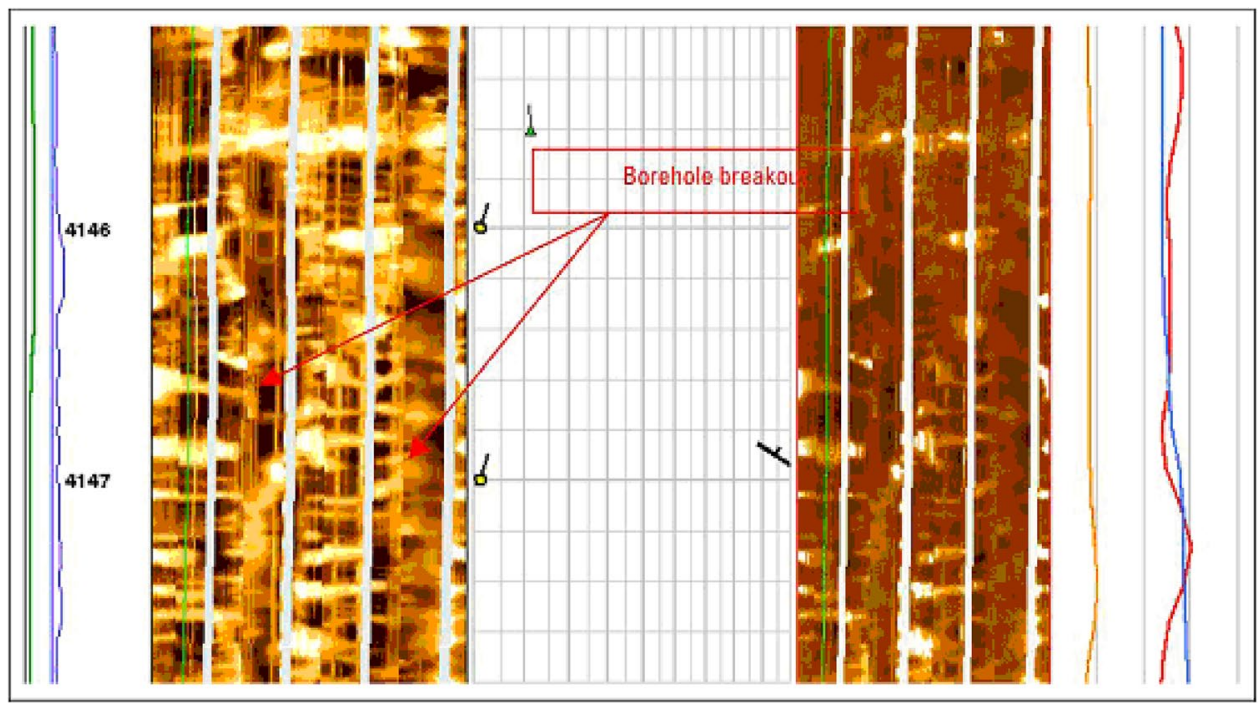

In examining the depths of further depths, the fractures determined from the graph images completely correspond to the fractures in the core (Fig. 10).

\section{Conclusion}

1. The Zubair carbonate reservoir, the petro-physics section was divided into 10 zones based on porosity, water saturation, and shale volume variation. The dominant lithol-

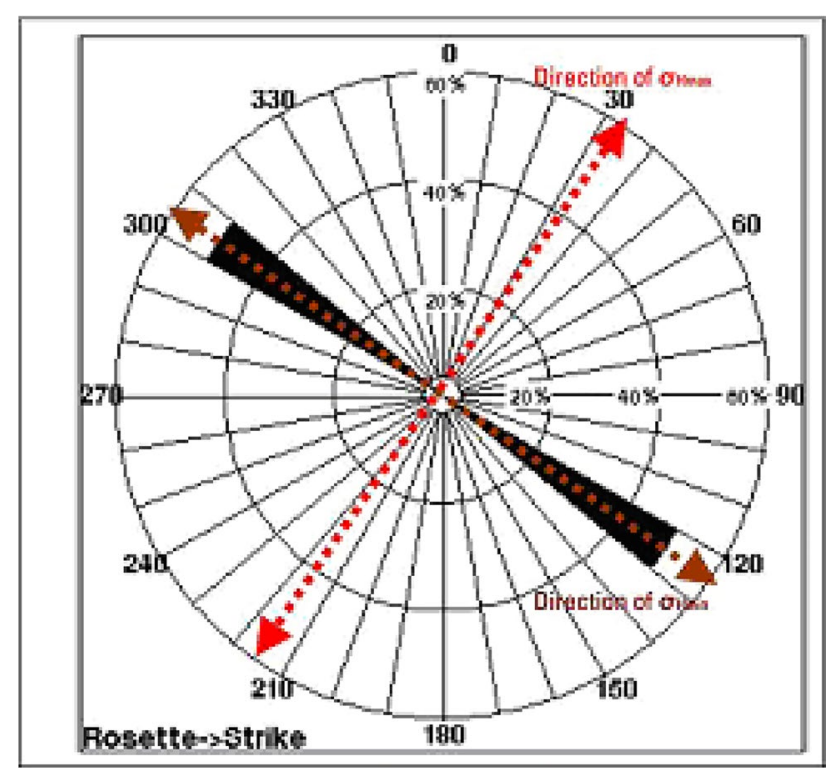

Fig. 9 Lowest horizontal stress diagram in direction of NNE-SSW, depth $4147 \mathrm{~m}$. The porosity of the cavity type is 3 to 4 percent in most distances of Zubair Formation and over 10 milliards permeation in the 3425 (D 3440-3435 m), 3473 (E1, 3483,3525-3500 m), 3623 3600) E2, 3635-3630 m (3865) G, 3875, 3895-3883 m, (4120-4055) I, 4136-4132 m, is reported ogy of this formation is more than limestone and a small number of thin shale layers. Types of cross-sectional petro-physical graphs have been shown and confirmed by the geological graphic diagram prepared at the head.

2. The petro-physical analysis was done in two definite and probable methods depending on mathematical modeling and analytical correlations. While petro-physical analysis is probably due to the common problems of charting and the uncertainty of all the graphs during the operation of a great deal of flexibility compared to the lack of data. On the other hand, the results of this analysis make it possible to adapt more and more easily to the realities of the reservoir. Hence, in this study, the use of applied petro-physics in natural gas projects has been emphasized with great emphasis.

3. The useful column of hydrocarbon in the upper Zubair zones is more than the base zones of this formation. This is due to proper porosity, reduction of capillary strength, and, finally, the ease of movement of gas above the reservoir.

4. Investigation of the amount of shale in the Zubair Formation shows that in this formation the average amount of shale volume calculated in sections $3,4,8$, and 10 is less than other zones, and zones 5 and 6 are in terms of shale volume to the extent Moderate zones 1 and 2 have significant shale volume and are not considered as useful parts of the reservoir, and this parameter in low-shale zones has resulted in reservoir quality in comparison with other parts of it.

5. The mean structural slope of Zubair Formation in the layered slope resulting from the interpretation of the structure of the microstructure tool in depth distances of 3417 to $4167 \mathrm{~m}, 7^{\circ}$ to the west of $30^{\circ}$ north (N30W).

6. Based on 32 fractures taken from the images of the microstructure form graph, 3 fractures were shown in

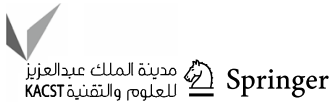


Fig. 10 Adjustment of open corona fracture with the shape of microstructure diagram at depth of $3559 \mathrm{~m}$

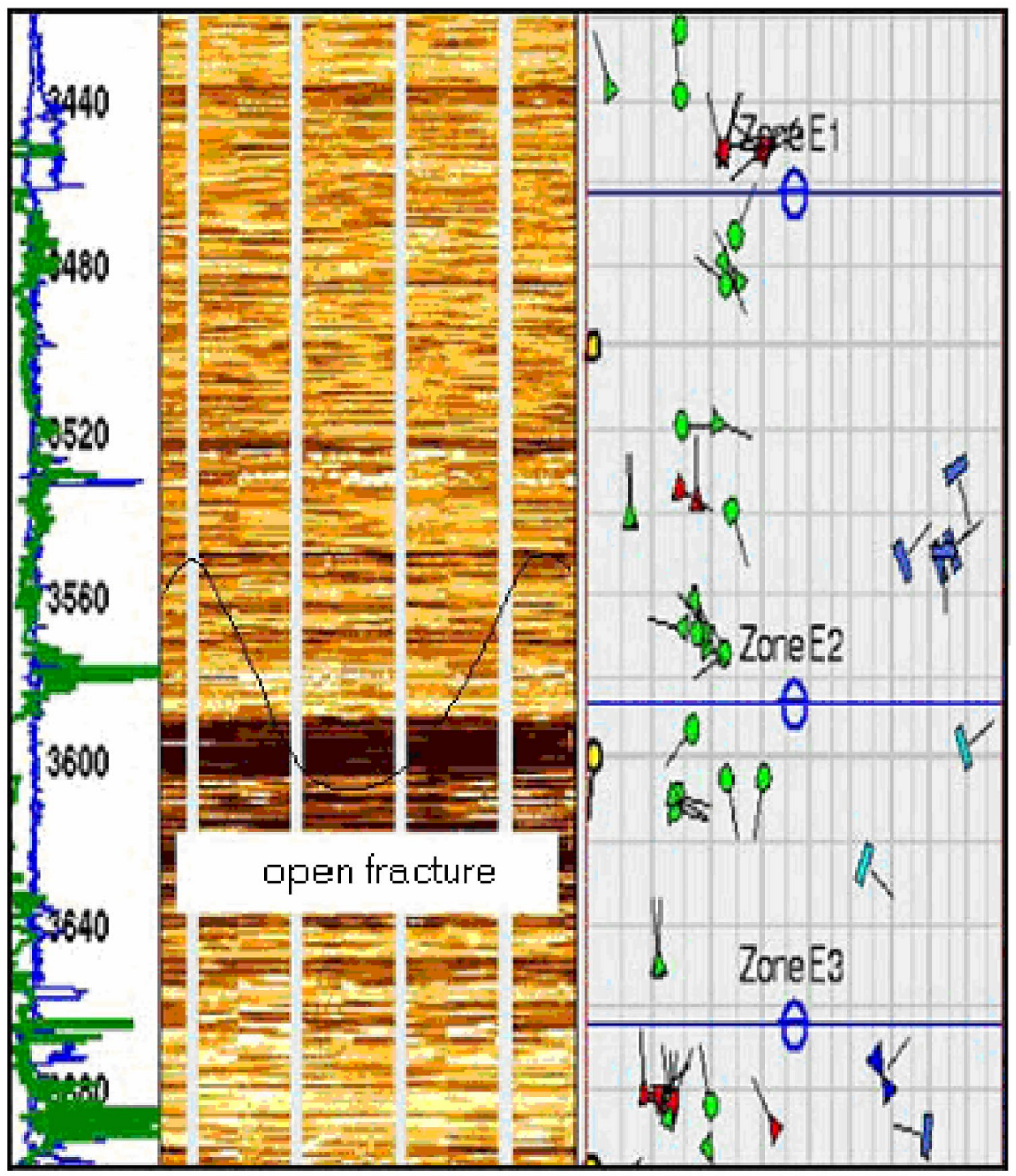

this well that 3 cavity fractures with $57^{\circ}$ east along the east, 15 possible open fractures with slope of $57^{\circ}$ to $77^{\circ}$, and 2 strokes N25E)-(S25W) and (N75W)-(N75E), 14 closed fractures with a slope of $52^{\circ}$ to $80^{\circ}$ and 3 coordinates with coordinates (S75E)-(N75W) and (N25W)(S25E) and (N60E)-(S60W).

7. The presence of fractures due to damage to the well wall and represent the lowest horizontal stress $\delta(1)$ in the direction of NNE-SSW and a depth of $4147 \mathrm{~m}$, between the probable open fracture at $3559 \mathrm{~m} / \mathrm{s}$ depth and the core formed by the shape of the FMI (Fig. 10).

Funding No funding.

\section{Compliance with ethical standards}

Conflict of interest On behalf of all the co-authors, the corresponding author states that there is no conflict of interest.

Open Access This article is licensed under a Creative Commons Attribution 4.0 International License, which permits use, sharing, adaptation, distribution and reproduction in any medium or format, as long as you give appropriate credit to the original author(s) and the source, provide a link to the Creative Commons licence, and indicate if changes were made. The images or other third party material in this article are included in the article's Creative Commons licence, unless indicated otherwise in a credit line to the material. If material is not included in the article's Creative Commons licence and your intended use is not permitted by statutory regulation or exceeds the permitted use, you will need to obtain permission directly from the copyright holder. To view a copy of this licence, visit http://creativecommons.org/licenses/by/4.0/. 


\section{References}

Al-Rubaie A, Ben Mahmud H (2020) A numerical investigation on the performance of hydraulic fracturing in naturally fractured gas reservoirs based on stimulated rock volume. J Pet Explor Prod Technol 10(8):3333-3345. https://doi.org/10.1007/s13202-02000980-8

Ben Y, Miao Q, Wang Y, Shi G (2012) Effect of natural fractures on hydraulic fracturing. In: Paper ISRM-ARMS7-2012-087 presented at the ISRM regional symposium-7th Asian rock mechanics symposium, Seoul, Korea

Cho Y, Ozkan E, Apaydin OG (2013) Pressure-dependent naturalfracture permeability in shale and its effect on shale-gas well production. SPE Reserv Eval Eng 16(02):216-228. https://doi. org/10.2118/159801-PA

Fisher MK, Wright CA, Davidson BM, Goodwin AK, Fielder EO, Buckler WS, Steinsberger NP (2002) Integrating fracture mapping technologies to optimize stimulations in the Barnett shale. In: Paper SPE 77441 presented at the SPE annual technical conference and exhibition, San Antonio, Texas. https://doi. org/10.2118/77441-MS

Ge J, Ghassemi A (2012) Stimulated reservoir volume by hydraulic fracturing in naturally fractured shale gas reservoirs. In: Paper ARMA-2012-468 presented at the 46th U.S. rock mechanics/ geomechanics symposium, Chicago, Illinois

Hu D, Matzar L, Martysevich VN (2014) Effect of natural fractures on eagle ford shale mechanical properties. In: Paper SPE 170651 presented at the SPE annual technical conference and exhibition, Amsterdam, The Netherlands. https://doi.org/10.2118/170651-MS

King GE (2010) Thirty years of gas shale fracturing: what have we learned? In: Paper SPE 133456 presented at the SPE annual technical conference and exhibition, Florence, Italy. https://doi. org/10.2118/133456-MS
Luffel DL, Hopkins CW, Schettler PD Jr (1993) Matrix permeability measurement of gas productive shales. In: Paper SPE 26633 presented at the SPE annual technical conference and exhibition, Houston, Texas. https://doi.org/10.2118/26633-MS

Mayerhofer MJ, Lolon EP, Youngblood JE, Heinze JR (2006) Integration of microseismic-fracture-mapping results with numerical fracture network production modeling in the Barnett Shale. In: Paper SPE 102103 presented at the SPE annual technical conference and exhibition, San Antonio, Texas, USA. https://doi. org/10.2118/102103-MS

Mayerhofer MJ, Lolon E, Warpinski NR, Cipolla CL, Walser DW, Rightmire CM (2010) What is stimulated reservoir volume? SPE Prod Oper 25(1):89-98. https://doi.org/10.2118/119890-PA

Sakhaee-Pour A, Bryant S (2012) Gas permeability of shale. SPE Reserv Eval Eng 15(4):401-409. https://doi.org/10.2118/14694 4-pa

Warren JE, Root PJ (1963) The Behavior of Naturally Fractured Reservoirs. Soc Pet Eng J 3(3):245-255

Wu Q, Xu Y, Wang X, Wang T, Zhang S (2012) Volume fracturing technology of unconventional reservoirs: connotation, design optimization and implementation. Pet Explor Dev 39(3):377-384. https://doi.org/10.1016/S18763804(12)60054-8

Zhao YL, Zhang LH, Luo JX, Zhang BN (2014) Performanceof fractured horizontal well with stimulated reservoir volume in unconventional gas reservoir. J Hydrol 512:447-456. https://doi. org/10.1016/j.jhydrol.2014.03.026

Publisher's Note Springer Nature remains neutral with regard to jurisdictional claims in published maps and institutional affiliations. 